\title{
O vínculo entre infra estrutura e superestrutura na perspectiva contemporânea
}

Vicente Gomes ${ }^{1}$

Um dos insights mais fecundos no estudo do conhecimento humano concerne à compreensão de que esse fenômeno não constitui um fato independente. Ao contrário do que defendem as filosofias inatistas e aprioristas, o conhecimento é concebido como relativo a, ou dependente de determinado contexto. Uma das primeiras formulações reflexivas sobre essa relação coube ao marxismo. Talvez nenhuma outra proposição marxista seja tão conhecida quanto à de que a "infraestrutura determina a superestrutura". Essa matriz reflexiva abriu um imenso campo de investigação sobre o conhecimento, capitaneado pela chamada Sociologia do Conhecimento. As reflexões atuais avançaram muito na compreensão desse fenômeno, notadamente em relação a dois aspectos: ao processo de universalização da relativização do conhecimento e à discussão sobre a natureza do vínculo entre contexto e conhecimento. Com relação à relativização do conhecimento, nenhum ponto de vista, "progressista" ou "conservador", e nenhum tipo de conhecimento, seja empírico ou formal, foge a essa caracterização. Isso tem levado à ampliação da compreensão do fenômeno da ideologia. Com relação à natureza do vínculo entre contexto e conhecimento, a defesa de uma perspectiva determinista é cada vez mais suplantada por uma visão de uma correlação estatística.

De acordo com a sistematização da sociologia do conhecimento por Karl Man-

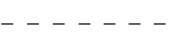

1 Vicente Gomes é Prof. do Departamento de Filosofia da UFPI e Doutorando pela Unicamp. Defendeu, em 1999, na própria Unicamp, a dissertação A Gênese e a Compreensão do Objeto Cultural em Karl Mannheim. 0 projeto de Doutorado é sobre a Explicação Científica em Sociologia do Conhecimento.

cadernos cemarx, $n^{0} 2-2005 \mid 127$ 
nheim o desenvolvimento rumo à autoconsciência da vinculação situacional do saber decorreu dos fatores: a) auto-relativização do conhecimento; b) uma forma de relativização do conhecimento especificamente moderna - o modo "desmascarador" da ciência oposicional; c) o contexto situacional moderno ao qual o conhecimento é relativo: a esfera social; e d) universalização da concepção relacional do conhecimento.

O fator a representa um ataque frontal à tese, comum aos racionalismos, da existência de conhecimentos inatos ou apriorísticos. A auto-relativização do pensamento consiste no fato de que os conhecimentos são fenômenos subordinados a outros fatores mais englobantes. Os conhecimentos são emanações, expressões ou determinados por instâncias globalizantes. Historicamente essas instâncias têm assumido diferentes formas. O pensamento já foi considerado relativo a uma consciência mítica, como na antigüidade, e determinado por uma consciência religiosa, como no pensamento medieval. Nesses casos, o pensamento é percebido como emanando de algo que se configura como uma realidade mais abrangente do qual ele é parte. Podemos identificar essa instância como a esfera da vida experimentada mais intensamente pelo sujeito conhecedor, a instância vivida como imediatamente mais real por ele, ou, ainda, a instância que representa o principal domínio dos problemas de uma época.

O fator $b$ está ligado a determinada atitude intencional em face do conhecimento. A constituição sistemática da sociologia se dá configurando aquilo que Mannheim denomina a "viragem da mentalidade desmascarante". A atitude sociológica burguesa de hostilidade à teologia, à metafísica, à monarquia e ao clero tinha como tarefa central a desintegração das idéias e concepções de mundo das classes medievais dominantes. E isso era feito, não se estabelecendo a refutação, a negação ou a dúvida sobre idéias e concepções, mas apontando a sua função extrateórica, vale dizer, seu vínculo com a esfera existencial. Bastante pertinente essa diferença, pois refutar, negar ou duvidar de uma idéia ou de uma concepção de mundo é, ainda, permanecer dentro do âmbito teórico em que ambas estão constituídas. Ao passo que apontar a função extrateórica de determinada concepção de mundo é "desmascará-la", é desgastá-la, na medida em que a vincula à prática existencial do seu defensor e, por isso mesmo, é "transcender" a sua imanência teórica.

Esse modo de depreciar as idéias adversárias passa a ser, desde então, a marca do contraste das classes sociais. A evolução desse modo de pensamento oposicional logo ultrapassa a sua fase preparatória, datada historicamente no processo de suplantação das classes medievais pela burguesia, atingindo seu primeiro estágio de consciência com a formulação reflexiva do marxismo. Aqui vemos a gênese do processo no qual

128 0 vínculo entre infra estrutura e superestrutura na perspectiva contemporânea 
os fatores históricos começam a ganhar relevo na formação da consciência moderna. E como esse processo representa uma mudança na sua compreensão, na medida em que impulsiona o desenvolvimento da consciência da relativização do conhecimento.

O processo de autoconsciência do pensamento sobre sua vinculação situacional ocorre num momento histórico em que ele é determinado por uma instância tipicamente moderna: o contexto existencial social. O modo de pensamento oposicional não só aponta uma nova maneira de transcendência do plano teórico - a maneira "desmascaradora" - como também aponta em direção à realidade que "determinará" a teoria a partir de então. É óbvio que a esfera social sempre existiu, desde que existiu homem sobre a terra. Mas, o social só passa a ser a esfera da vida experimentada mais intensamente pelo sujeito cognoscente a partir do processo de acirramento da luta de classes.

O social é identificado de forma bastante específica. Longe da visão jusnaturalista do social como fruto de vontades individuais pactuadas, o social moderno é uma instância essencialmente global e coletiva. É tão extravagante pretendermos explicar uma perspectiva de pensamento com referência apenas ao indivíduo, quanto seria achar que o indivíduo fala uma língua que é só dele, pois esta é, de fato, a língua dos seus contemporâneos e predecessores. Outros princípios da ontologia do ser social de inspiração marxista são identificados. Antes de tudo, não há separação antitética entre natureza e sociedade, ao contrário, a natureza é a base das atividades de produção e reprodução da vida humana. Da ação do homem sobre a natureza vingaram todas as categorias sociais tais como as habilidades do homem para o trabalho, a linguagem, as transformações no cérebro, o surgimento do pensamento etc.

O trabalho é a principal categoria dessa visão ontológica do ser social, e isso porque ele é o instrumento de produção e reprodução da vida humana. $\mathrm{O}$ processo de produção e reprodução da vida, como a condição da existência humana, cria e transforma todas as relações sociais entre os seres humanos, da constituição do conflito entre as classes à formação dos diversos tipos de sociedades, passando pela divisão do trabalho. O ponto alto desse processo de produção e reprodução da vida é o do nível social mais puro, mais específico, ou da transformação do "ser social em si" em "ser para si". Vale dizer, de constituição da dimensão cultural em sentido estrito, referente a objetos culturais tais como a religião, o direito, a política, as artes, a ciência etc.

Ao projetar para o centro da análise o problema da produção e da reprodução da vida humana, a visão marxista da sociedade torna possível uma descrição ontológica do ser social sobre bases eminentemente materialistas, ao mesmo tempo em que

cadernos cemarx, $n^{0}-2-2005 \quad 129$ 
põe como indissociáveis a constituição da individualidade, da cultura, enfim, da "natureza" humana e o contexto histórico no qual essa constituição se dá.

A característica fundamental do contexto social moderno é sua identificação ao econômico. E, dessa forma, a esfera econômica se constitui no principal domínio existencial dos problemas vitais em nossa época, pois ocupa, "cada vez mais, o centro da experiência e faculta as categorias fundamentais em termos das quais se experimentam todas as outras esferas da vida"2.

O quarto fator da constelação que torna possível uma sociologia do conhecimento pode ser caracterizado como um processo de passagem da visão constatativa do vínculo entre contexto e conhecimento para o estágio auto-reflexivo da sociologia do conhecimento. Podemos, ainda, caracterizar esse processo de universalização da consciência da relativização do conhecimento como um processo no qual o uso da categoria de "ideologia" vai sendo suplantado pelo uso da categoria de "perspectiva situacionalmente vinculada".

Embora a reflexão inicial sobre o vínculo em questão tenha sido operada pelo marxismo, em geral a visão de ideologia defendida pelos marxistas é considerada insuficiente para caracterizar o problema. Para esta visão a ideologia é a característica do conhecimento à serviço da classe dominante. As idéias oponentes são consideradas distorções, deformações ou inversões da situação social a que se referem. Nessa condição estas idéias terminariam por ocultar a situação social e, assim, serviriam aos interesses da classe dominante. O defeito da noção de ideologia nessa perspectiva é a incapacidade de aplicação desse traço fundamental do conhecimento humano ao próprio pensamento marxista. Segundo Micheal Lövy,

Não se pode negar que esta crítica contém uma parte de verdade: várias correntes no seio do marxismo, desde a época de Mannheim até nossos dias, influenciados pelo positivismo (é suficiente pensar em Kautsky e no 'marxismo ortodoxo' da II Internacional), apresentaram o materialismo histórico como sendo uma 'ciência' pura e simples, livre de julgamentos de valor, não ideológica (ou utópica) e sem vinculações de classe ${ }^{3}$.

- - - - - -

2 K. Mannheim, “O Problema da Sociologia do Conhecimento". In: Mannheim, Karl. Sociologia do Conhecimento. Tradução de Maria das G. Barbedo. Porto. Rés Editora, s/d, p. 230.

3 M. Lövy, As Aventuras de Karl Marx contra o Barão de Münchhausen. Tradução de Juarez Guimarães e Suzanne F. Léwy, São Paulo, Editora Ciências Humanas, 1979, p. 84.

130 O vínculo entre infra estrutura e superestrutura na perspectiva contemporânea 
O mais importante, no entanto, é que uma "intuição tão reveladora sobre a base do pensamento, como a que oferece a noção de ideologia, não pode permanecer, por muito tempo, como privilégio exclusivo de uma classe"4. Um novo estágio na análise do pensamento em geral é atingido precisamente em função da expansão e da difusão da abordagem ideológica.

Segundo Mannheim, chegamos a uma posição na qual não é mais possível "para um ponto de vista e para uma interpretação refutar os demais por serem ideológicos,

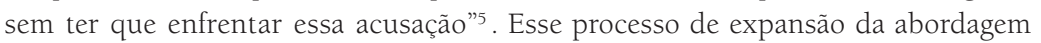
ideológica termina sendo a causa de uma transformação realmente dialética do significado de ideologia. Quando todos passam a analisar o pensamento de todos em termos da sua vinculação situacional, temos que o conceito de ideologia já assumiu um significado totalmente diferente do anterior, pois agora já não pode ser concebido como parcial nem restrito.

Por conseguinte, como categoria que tenta dar conta da evolução e da expansão da idéia de vinculação do conhecimento e do pensamento a uma entidade da qual são partes, a "universalização" aqui deve ser entendida como uma mudança em duas dimensões: 1. Não só o pensamento da classe dominante mas todo e qualquer pensamento é determinado existencialmente; 2. A vinculação existencial do pensamento não significa distorção, deformação, mascaramento da realidade, mas determinação da função do pensamento a nível da estrutura mental.

O conceito de "perspectiva situacionalmente determinada" remete a uma característica fundamental do pensamento contemporâneo. Essa característica fundamental é a de que o conhecimento é necessariamente perspectivado, de que a estrutura mental é diferente, nos diversos pontos de vista, na medida em que "não são" os "mesmos" objeto e realidade que são percebidos pelos homens que vivem em contextos existenciais variados.

Atualmente, inúmeras pesquisas de casos concretos buscando caracterizar o vínculo em questão são realizadas em praticamente todos os campos do conhecimento humano, inclusive no campo do pensamento lógico e matemático, como defende e empreende o chamado "programa forte" para a sociologia do conhecimento.

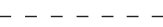

4 K. Mannheim, Ideologia e Utopia. Tradução de Sérgio M. Santeiro, Rio de Janeiro. Editora Guanabara, 1986, p. 100.

5 Idem, p. 100.

cadernos cemarx, $\mathrm{n}^{0} 2-2005 \quad \mathbf{1 3 1}$ 
Contudo, o que significa ser um conhecimento "determinado" por um contexto existencial? Existem posições extremadas no debate. Grosso modo, o uso científico do vocábulo determinado "indica uma espécie de 'conexão constante e unívoca' entre acontecimentos, coisas ou qualidades das coisas" . Alguns sociólogos do conhecimento, como David Bloor defendem uma concepção próxima dessa caracterização. Ao explicitar os princípios do strong programme para a sociologia do conhecimento ele assim define o primeiro deles:

A sociologia do conhecimento deve estabelecer as causas das crenças, isto é, leis gerais relacionando as crenças às condições que são necessárias e suficientes para determiná-las ${ }^{7}$.

Para Bloor, a busca de regularidades, a formulação de princípios gerais ou de leis deve ser a principal preocupação do sociólogo do conhecimento, porque é o que caracteriza a linguagem científica em qualquer campo. Para o programa forte, as ciências sociais devem procurar detectar regularidades enquadráveis como leis científicas da mesma forma que as demais ciências. A demarcação da unidade da ciência aqui suplanta aquela presente na concepção racionalista popperiana, porque Bloor defende a sua aplicação mesmo ao campo da história, o que é rejeitado por Popper.

Há, portanto, uma importante corrente que considera o modelo legalóide e causal como o paradigma de toda explicação "genuína", a forma ideal para a qual devem tender os esforços para elaborar explicações. Mas, há resistências a essa tentativa. Ernest Nagel, face às sugestões de substituição das suposições estatísticas, nas premissas de explicações probabilísticas, por enunciados de caráter universal, considera difícil, em muitas disciplinas, afirmar a plausibilidade de leis universais, mas tão-somente estabelecer com certa garantia regularidades estatísticas. Em conseqüência, conclui Nagel que "não é possível ignorar as explicações probabilísticas, sob pena de se excluir do exame relativo à lógica da explicação importantes campos da investigação"8.

Por seu turno, ao referir-se à relação entre conhecimento e situação social Mannheim usa termos como: condicionamento, vínculo, função, correlação, ligação, determinação etc., expressões que deixam em aberto, alerta ele, o caráter exato da determinação existencial do conhecimento. Mannheim assume a tensão que permeia o

6 L. Hegenberg, Explicações Científicas. São Paulo, EPU/Edusp, 1973, p. 179.

7 D. Bloor, "Wittgenstein and Mannheim on the Sociology of Mathematics". In: Studies in History of Science. August, 1973 , vol. 4, № 2, p. 173 (grifo meu).

8 Ernest Nagel, La Estructura de la Ciencia. Versión castellana de Néstor Míguez. Buenos Aires, Paidos, s/d, p. 34.

132 O vínculo entre infra estrutura e superestrutura na perspectiva contemporânea 
uso da categoria de determinação na caracterização da tese central da sociologia do conhecimento. Escreve ele:

Por "determinação" não nos referimos (...) a uma seqüência mecânica de causa-efeito: deixamos em aberto o significado de "determinação", e somente a investigação empírica nos poderá mostrar até que ponto é estrita a correlação entre situação de vida e processo de pensamento, ou qual a gama de variações existente na correlação ${ }^{9}$.

A questão é, além de controversa, muito complexa. Como o recurso à análise de estudos de casos tem sido a regra na elaboração das formulações da sociologia da ciência, devemos continuar utilizando esse método para tentar elucidar a questão. Um dos estudos de casos mais citados nas formulações recentes em sociologia da ciência, notadamente por aquelas constitutivas da perspectiva causal de Bloor, é o de D. Mackenzie sobre o desenvolvimento da Estatística na Inglaterra, no final do século XIX. As conclusões de Mackenzie sobre a natureza do vínculo em questão são extremamente ponderadas, precipuamente com relação ao modelo advogado por Bloor. Escreve Mackenzie, ao final do seu estudo:

O estágio final da análise é necessariamente 'experimental' (tentative). Nesta seção examinarei os interesses sociais subjacentes à eugenia na Inglaterra, a fim de sugerir que os interesses sociais oriundos da mudança da estrutura social naquele país são um possível fundamento para a controvérsia. A eugenia será analisada como uma ideologia que expressa os interesses de um segmento particular da sociedade britânica e não aqueles de outros segmentos. Ao argumentar assim, eu não estou fazendo qualquer postulação em proporcionar uma explicação causal para as crenças de indivíduos particulares. Para tomar uma analogia da sociologia política, dizer que um partido político P expressa os interesses do grupo G não é dizer que todos os seus membros, ou sequer que a maioria dos membros de G votam em P. É, ao contrário, asseverar que, se as políticas de $\mathrm{P}$ fossem postas em prática, incrementariam a riqueza, o status, o poder, a segu-

9 K. Mannheim, Ideologia e Utopia. Tradução de Sérgio M. Santeiro. Rio de Janeiro, Editora Guanabara, 1986, p. 289.

cadernos cemarx, $n^{0}-2-2005 \quad 133$ 
rança etc. de G. Apoio diferencial para P entre membros e não membros de $G$ poderia ser antecipado, mas o ponto é que o âmago do argumento é estrutural e não individual. Assim, ao examinar possíveis conexões entre as pesquisas relevantes em eugenia e interesses sociais, não estou certamente postulando que esses interesses são necessários e suficientes para explicar o trabalho científico e crenças de indivíduos particulares. Pearson, Yule e outros estatísticos discutidos aqui foram indivíduos que freqüentemente seguiram padrões de carreiras complexas e desenvolveram freqüentemente comprometimentos idiossincrásicos. Contudo, suas escolhas de crença e afiliação não foram tomadas em um vácuo, mas em uma dada situação histórica e social. Estudar esta situação pode iluminar satisfatoriamente suas escolhas, mesmo se esse estudo não proporciona uma consideração causal delas ${ }^{10}$.

Apesar de termos citado apenas um caso concreto como esteio para análise do nosso objeto neste texto, suas conclusões parecem assumir um ar "paradigmático" em relação aos demais estudos. A conclusão a que chegou Mackenzie parece sugerir um modelo mais "flexível" da determinação do conhecimento pelo contexto situacional do que aquele defendido particularmente pelo programa forte. Talvez, isso se deva ao caráter significativo do objeto cultural. O significado é algo complexo e essa complexidade impede que pensemos as reações significativas como invariáveis, como deveria ser na perspectiva do modelo nomológico causal. A mente humana tem a capacidade de combinar as determinações existenciais de modos variados, por isso os comportamentos significativos podem ser apenas aproximadamente, mas nunca totalmente previsíveis. A complexidade e a interdependência dos significados impedem que a natureza dessa correlação entre conhecimento e contexto seja do tipo mecânico.

10 D. Mackenzie, “Statistical Theory and Social Interests". In: Social Studies of Science, SAGE, London and Beverly Hills, vol. 8, 1978, p. 66 (grifo meu).

134 O vínculo entre infra estrutura e superestrutura na perspectiva contemporânea 